\title{
THE INFESTATION OF YOUNG OKRA PODS BY PINK BOLLWORM IN PORTO RICO
}

By George N. WoLcotт, Entomologist, Isabela Sub-Station.

Summary: Infestation by Pectinophora gossypiella Saunders of tender young okra pods, not more than three inches long, nor more than three days old, occurs in Porto Rico when the okra plants are close to cotton fields maturing bolls which are heavily or totally infested by pink bollworm.

The average annual rainfall in the northwestern corner of Porto Rico is usually sufficient so that most of the agricultural crops of the Island could be grown there if the distribution of the rainfa!l thruout the year was not so uneven, and the periods when most of it occurs were not so uncertain. During the last few years, irrigation water has been available in this section, the Isabela Irrigation District, but the extremely low and unsatisfactory prices received by growers for cotton and sugarcane, the main crops of the region, make desirable the introduction of other more profitable crops.

One of the most promising developments appears to be the produetion of vegetables for the winter market in New York, and several kinds of vegetables have already been grown here, and exported on a small scale. Among others which gave promise of being profitable was okra, but the importation of okra pods from Porto Rico into continental United States is prohibited by federal quarantine. As the market demands for okra require pods to be not more than three inches long, it seemed possible that such tender and recently developed pods might escape infestation by the pink bollworm, Pectinophora gossypiella Saunders. Thus, an investigation for the collection of pertinent data seemed desirable, looking towards the possible formulation of a request for a modification of this quarantine.

The sole record of infestation by pink bollworm of okra pods in Porto Rico (1), at the time the writer commenced work on vegetable insects this spring, was that made by Mr. J. D. More at Humacao in 1921, when pink bollworm was first discovered in the Island. The Plant Quarantine and Control Administration agents stationed in Porto Rico for a number of years since had added nothing but negative evidence to this lone record, and it seemed likely that infestations were most exceptional. The illustration of caterpillars in pods, given by Loftin in his publication on this insect in Mexico (2) were of large, mature pods, and when questioned in person, he stated that 
he had no remembrance of finding the larvae in the smaller pods. Several okra pods examined at various points between Isabela and Aguadilla, at a time when cotton plants had not yet begun to mature bolls, gave further negative evidence. Indeed the first positive indication that okra might be infested was an observation made at the opposite end of the Island.

While making examinations of cotton bolls to determine the amount of infestation by pink bollworm, in one rather extensive planting near the beach east of Loíza Viejo, infestation was found to be not only total for the bolls, but so heavy that all the bolls were destroyed. The grower explained that the first crop of cotton grown here had been so excellent and profitable that he had promptly followed it with another planting immediately after plowing up the first, which, most inexplicably to him, had proved to be a complete failure. By thus having no non-cotton season, he had built up such a large population of pink bollworm in this comparatively isolated region that it was not surprising to find that a single okra plant nearby with mature green pods was infested with its caterpillars, four pods having one larva each, and one pod containing two caterpillars. This observation, however, represented a most exceptional condition, and none of the smaller pods were infested, even of this plant in the midst of a large moth population presumably experiencing the greatest difficulty in finding suitable hosts for oviposition. Yet it indicated possibilities, which were later confirmed by Messrs. Mills and Berry, of the Plant Quarantine and Control Administration, who are unofficially reported to have found ten out of sixteen pods of okra infested at Trujillo Alto in a small planting adjacent to a cotton field known to be heavily infested with pink bollworm.

The real point at issue, however, had not been determined: whether the immature green pods would be infested. Observations made at the Isabela Sub-Station indicated that pods attained the maximum marketable size in three days from the dropping of the corolla, and ordinarily pods must be picked every other day to keep them from becoming too tough to be acceptable to the market. The period when they might possibly become infested before being picked was so short that it was thought that in commercial plantings infestations would not occur. To determine this point with certainty, a considerable planting of okra was made, consisting of a row around the cotton fields of two demonstration farms of the district, at Maleza and at Bejucos. The cotton on both of these farms was beginning to mature at the time the okra was planted, and while it was known to be infested with pink bollworm, these infestations were supposed to be 
representative of near-by commercial cotton fields, and of the district as a whole.

The farm at Bejucos is in the midst of a cotton district, and later observations have indicated that pink bollworm was not exceptionally abundant there. The farm at Maleza, however, is in a region previously devoted largely to growing hat palms, and while scattered patches may be planted to cotton, the farmers generally know little about its culture. It is presumed that no care had been taken at the end of the previous crop season to destroy old cotton plants from one of these near-by patches, and the fertilized cotton of the demonstration farm was noted to be heavily infested with pink bollworm as soon as it began to mature bolls. By the time that the okra plants began to form pods, infestation of cotton bolls by pink bollworm was total. Nevertheless, the first two pods of okra attaining marketable size at Maleza were free from pink bollworm injury, as were the next fifty, nor were eggs observed on any of them.

The next collection of okra pods from Maleza was made July 30th, but their examination was not commenced until August 1st, and the smallest pods were not eut open until the $3 \mathrm{~d}$. The longest of these pods were 5 inches in length, 20 out out of the total of 176 being from 5 to 4.5 inches long, 20 from 4.5 to 4 inches, and 20 from 4 to 3.5 inches long, but the remainder were of the most desirable marketable size, or even smaller, being less than 3 inches long in some cases. In two of the largest pods larvae already beginning to turn pink were found. Smaller caterpillars were found in the younger pods, but the percentage of infestation did not greatly decrease with a decrease in the size and presumptive age of the pods. For the total collection, infestation was about 6 per cent. Observations made five days later at Maleza gave results practically identical with those previously obtained there: an infestation of about 6 per cent. From over a hundred pods collected there the next day, of which the majority were examined, only one was found infested with pink bollworm, but this pod was only two and a half inches long.

In the meantime okra pods attained marketable size at Bejucos. and indeed had grown so luxuriantly that some of those of tenter age were much too large, some of them being seven inches long. Despite their large size, none were infested with pink bollworm (Ang. $3 d)$. Five days later, all of one hundred pods, from six to three inches long, were free from pink bollworm injury.

These results would appear to indicate that, while under ordinary conditions, infestation of okra pods does not occur even in the midst of cotton fields with normal pink bollworm infestations, even the 
youngest pods may become infested when near-by cotton is heavily infested. Such heavy infestations in cotton fields may be so readily built up by inexperienced or careless growers as to constitute a perpetual threat to commercial okra production. Naturally, of course, any reasonable hope of expecting possible changes in quarantine regulations governing okra must be abandoned.

\section{REFERENCES Cited :}

1. Wolcott, G. N. Insectae Portoricensis. Jour. Dept. Agr. P. R., Vol. 7, No. 1, pp. 313. San Juan, January, 1923. (see p. 202.) 2. Loftin, U. C., IICKinley, K. B. \& Hanson, W. K. Report on Investigations of the Pink Bollworm of Cotton in Mexico. U. S. Dept., Agr. Bull. No. 918, pp. 64, fig. 11, pl. 5. April 19, 1921. 